\title{
Can Pb-Free Halide Double Perovskites Support High-Efficiency Solar Cells?
}

\author{
Christopher N. Savory, ${ }^{\dagger}$ Aron Walsh, ${ }^{\ddagger}, \mathbb{I l}$ and David O. Scanlon $*, \dagger, \S$
}

${ }^{\dagger}$ Kathleen Lonsdale Materials Chemistry, Department of Chemistry, University College London, 20 Gordon Street, London WC1H 0AJ, United Kingdom

${ }^{\ddagger}$ Department of Materials, Imperial College London, Exhibition Road, London SW7 2AZ, United Kingdom

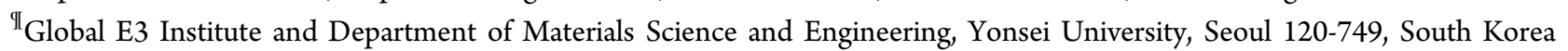

${ }^{\S}$ Diamond Light Source Ltd., Diamond House, Harwell Science and Innovation Campus, Didcot, Oxfordshire OX11 0DE, United Kingdom

\section{Supporting Information}

ABSTRACT: The methylammonium lead halides have become champion photoactive semiconductors for solar cell applications; however, issues still remain with respect to chemical instability and potential toxicity. Recently, the $\mathrm{Cs}_{2} \mathrm{AgBiX}_{6}(\mathrm{X}=\mathrm{Cl}, \mathrm{Br})$ double perovskite family has been synthesized and investigated as stable nontoxic replacements. We probe the chemical bonding, physical properties, and cation anti-site disorder of $\mathrm{Cs}_{2} \mathrm{AgBiX}_{6}$ and related compounds from first-principles. We demonstrate that the combination of $\operatorname{Ag}(\mathrm{I})$ and $\mathrm{Bi}$ (III) leads to the wide indirect band gaps with large carrier effective masses owing to a mismatch in angular momentum of the frontier atomic orbitals. The spectroscopically limited photovoltaic conversion efficiency is less than $10 \%$ for $\mathrm{X}=\mathrm{Cl}$ or $\mathrm{Br}$. This limitation can be overcome by replacing Ag with In or $\mathrm{Tl}$; however, the resulting compounds are predicted to

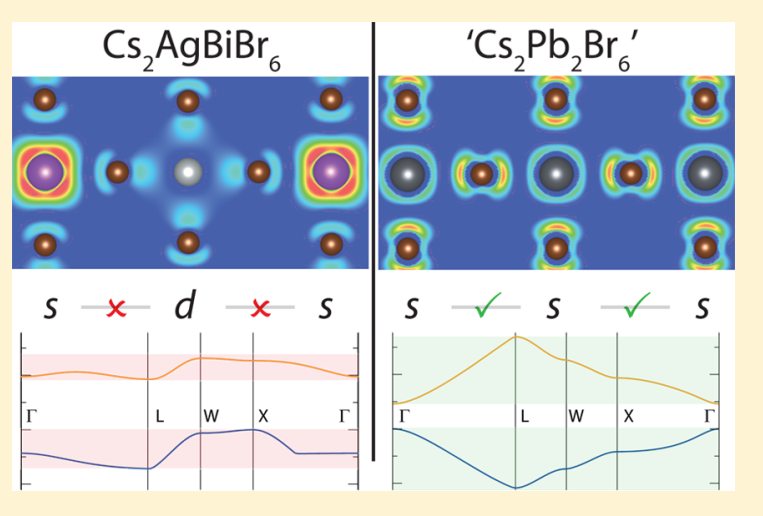

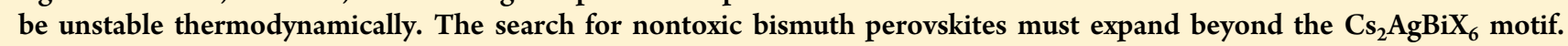

I $\mathrm{n}$ the 7 years since their first use in dye-sensitized solar cells, ${ }^{1}$ photovoltaic (PV) devices based on hybrid inorganic-organic lead halide perovskites have soared in efficiency to over $22 \%$, matching record $\mathrm{CdTe}$ and multicrystalline-Si cells and narrowing the gap to $\mathrm{Cu}(\mathrm{In}, \mathrm{Ga}) \mathrm{Se}_{2}$ and single-crystal $\mathrm{Si}^{2,3}$ The lead halide perovskites possess a number of advantages for PV applications in addition to a direct band gap of $1.6 \mathrm{eV}^{4}$ including scalable synthesis methods, ${ }^{5-7}$ strong absorption with a low Urbach energy, ${ }^{8}$ long carrier diffusion lengths and lifetimes, 9,10 and defect tolerance and self-regulation. ${ }^{11,12}$ Two major concerns are their instability in air ${ }^{13-16}$ and the inclusion of lead, the toxicity of which could present major barriers to commercialization. ${ }^{17}$

To counteract these issues, there have been multiple recent movements to improve upon the hybrid lead halides. ${ }^{18}$ One of these is the partial replacement of methylammonium with cesium in devices, to improve stability without impacting performance, with some substantial success. ${ }^{19,20}$ Other attempts have included moving to layered thiocyanate systems $\mathrm{s}^{21-23}$ and replacing methylammonium with much larger cations like phenylethylammonium, reducing dimensionality while improving stability, with record cells reaching $15 \%$ efficiency. ${ }^{24-26}$ Further investigations have included photoactive cations ${ }^{27-29}$ or moving beyond the perovskite structure altogether. ${ }^{30-33}$ So far this year, there have been multiple investigations into moving from the $\mathrm{A}^{\mathrm{I}} \mathrm{M}^{\mathrm{II}} \mathrm{X}_{3}$ perovskite to the $\mathrm{A}_{2}^{\mathrm{I}} \mathrm{M}^{\mathrm{I}} \mathrm{M}^{\mathrm{III}} \mathrm{X}_{6}$ double perovskite. Doing so allows the replacement of lead by the much less toxic bismuth $\left(\right.$ as $\mathrm{Bi}^{3+}$ ) and $1^{+}$cations such as $\mathrm{Ag}^{+}$ through cation mutation, analogously to the relation between $\mathrm{CuInS}_{2}$ and $\mathrm{Cu}_{2} \mathrm{ZnSnS}_{4}$. The $\mathrm{Cs}_{2} \mathrm{NaBiX}_{6}$ double perovskites, called elpasolites, have been known and studied since the $1970 \mathrm{~s} ;{ }^{34-36}$ however, replacing $\mathrm{Na}$ with $\mathrm{Ag}$ has been a novel development.

Slavney et al. first synthesized the cubic $F m \overline{3} m$ double perovskite $\mathrm{Cs}_{2} \mathrm{AgBiBr}_{6}$ (see Figure 1), estimating an indirect band gap of $1.95 \mathrm{eV}$ from UV-vis spectroscopy, and discuss its photoluminescence (PL) behavior. ${ }^{37}$ They found a long PL decay time of $660 \mathrm{~ns}$, which reflects the recombination lifetime, and also note that, given the indirect band gap, this is dominated by nonradiative pathways. McClure et al. were able to synthesize both $\mathrm{Cs}_{2} \mathrm{AgBiBr}_{6}$ and $\mathrm{Cs}_{2} \mathrm{AgBiCl}_{6}$, reporting indirect band gaps of 2.19 and $2.77 \mathrm{eV}$, respectively, from

Received: September 24, 2016

Accepted: October 12, 2016

Published: October 12, 2016 


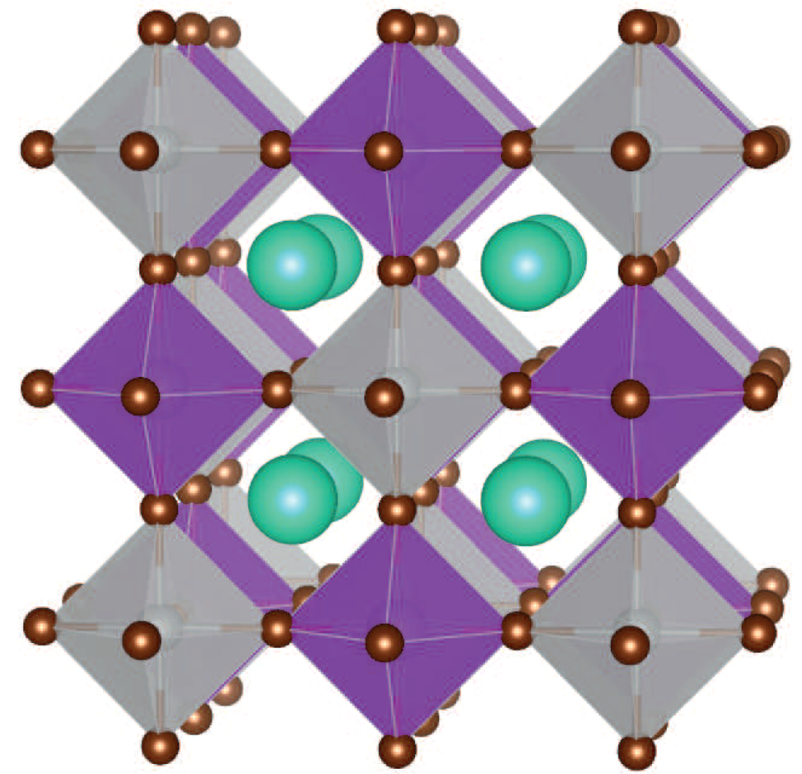

Figure 1. Cubic crystal structure of the halide double perovskite $\mathrm{Cs}_{2} \mathrm{AgBiBr}_{6}$. All of the cesium double perovskites $\left(\mathrm{Cs}_{2} \mathrm{MM}^{\prime} \mathrm{X}_{6}\right)$ in this Letter also use this structure. Silver atoms are in light gray, bismuth is in purple, cesium is in turquoise, and bromine is in brown.

diffuse reflectance spectroscopy and 2.06 and $2.62 \mathrm{eV}$ from density functional theory (DFT) calculations, with the latter confirming the indirect nature of the band gap. ${ }^{38}$ Volonakis et al. have performed a theoretical screening of the double perovskites, examining $\mathrm{M}^{\mathrm{I}}=\mathrm{Cu}, \mathrm{Ag}, \mathrm{Au}$ and $\mathrm{M}^{\mathrm{III}}=\mathrm{Bi}, \mathrm{Sb}$ and predicting that band gaps for these materials can range from 0.5 to $2.7 \mathrm{eV}$ and from 0.0 to $2.6 \mathrm{eV}$ for $\mathrm{Bi}$ and $\mathrm{Sb}$ systems, respectively. ${ }^{39}$ Cheetham and co-workers have synthesized two methylammonium double perovskites. These are $\left(\mathrm{CH}_{3} \mathrm{NH}_{3}\right)_{2} \mathrm{KBiCl}_{6}$, though like $\mathrm{Cs}_{2} \mathrm{AgBiCl}_{6}$, its indirect band gap was large, around $3 \mathrm{eV},{ }^{40}$ and $\left(\mathrm{CH}_{3} \mathrm{NH}_{3}\right)_{2} \mathrm{TlBiCl}_{6}$, possessing a direct but still large band gap of $2.16 \mathrm{eV}^{41}$ Even more recent work has seen the prediction of band gaps for $\mathrm{Cs}_{2} \mathrm{AgBiX}_{6}(\mathrm{X}=\mathrm{Cl}, \mathrm{Br})$, with many-body GW theory, ${ }^{42}$ of 2.4 and $1.8 \mathrm{eV}$, in reasonable agreement with experiment. An assessment of the defect chemistry of $\mathrm{Cs}_{2} \mathrm{AgBiBr}_{6}$ reported that $\mathrm{V}_{\mathrm{Bi}}$ and $\mathrm{Ag}_{\mathrm{Bi}}$ form deep acceptor levels, and thus growth under $\mathrm{Br}$-poor/Bi-rich conditions could enhance performance. ${ }^{43}$

The band gaps of all of the currently synthesized compounds are all likely too high for use in single-junction solar cells, yet Volonakis et al. demonstrate the possibility of lower band gap materials using iodides or alternate noble metals. ${ }^{39}$ Concerns remain, however, regarding their indirect band gaps, which will limit optical absorption, and their chemical stability; while Slavney et al. found no decomposition of $\mathrm{Cs}_{2} \mathrm{AgBiBr}_{6}$ under nitrogen, McClure et al. observed significant degeneration in its reflectance after a month when stored in light and air. In this Letter, we examine the origins of these issues through a theoretical examination of the $\mathrm{Cs}_{2} \mathrm{MBiX}_{6}$ series and related compounds and make an assessment of their utility in solar energy conversion.

All crystal structures mentioned in this report were optimized using the PBEsol functional; a comparison of the relaxed structures of $\mathrm{Cs}_{2} \mathrm{AgBiCl}_{6}$ and $\mathrm{Cs}_{2} \mathrm{AgBiBr}_{6}$ to the experimental structures of McClure et al. are displayed in Table 1, indicating that PBEsol is able to replicate these structures well, with
Table 1. Equilibrium Lattice Parameters, Following Optimization Using PBEsol/DFT with Percentage Differences from Experiment ${ }^{38}$ Given in Parentheses

\begin{tabular}{ccc} 
compound & $a / \AA$ & $c$ \\
$\mathrm{Cs}_{2} \mathrm{AgBiCl}_{6}$ & $10.6959(-0.75 \%)$ & $1223.64(-2.25 \%)$ \\
$\mathrm{Cs}_{2} \mathrm{AgBiBr}_{6}$ & $11.2011(-0.43 \%)$ & $1405.342(-1.29 \%)$ \\
\hline
\end{tabular}

neither lattice parameter differing by greater than $1 \%$ from experiment. Additionally, structures for the potential double perovskite compounds $\mathrm{Cs}_{2} \mathrm{AgBiI}_{6}, \mathrm{Cs}_{2} \mathrm{InBiX}_{6}(\mathrm{X}=\mathrm{Cl}, \mathrm{Br})$, and $\mathrm{Cs}_{2} \mathrm{TlBiX}_{6}(\mathrm{X}=\mathrm{Cl}, \mathrm{Br})$ were constructed by replacing the respective atoms within the known structures and performing a volume relaxation.

From these crystal structures, the electronic band structures for each compound were predicted using HSE06+SOC. The band structure of $\mathrm{Cs}_{2} \mathrm{AgBiBr}_{6}$ is displayed in Figure 2a and acts as an exemplar for the $\mathrm{Cs}_{2} \mathrm{AgBiX}_{6}$ series; our obtained band gap is $1.79 \mathrm{eV}$ and indirect, with the VBM at the $\mathrm{X}$ point of the Brillouin zone, while the conduction band minimum (CBM) is at $\mathrm{L}$ (the valence band maximum, VBM, in the chloride lies at $\Gamma)$. This is in accordance with the band structures presented by McClure et al. and Volonakis et al. The lowest direct (momentum-conserving) transition comes at X, with an energy of $2.45 \mathrm{eV}$. As seen in the methylammonium lead perovskites and the results of Volonakis et al., as the halide in $\mathrm{Cs}_{2} \mathrm{AgBiX}_{6}$ varies from $\mathrm{Cl}$ to $\mathrm{I}$, the predicted fundamental band gaps in our calculations shrink from 2.35 to $1.08 \mathrm{eV}$. As such, this would leave the iodide, in analogy to methylammonium lead iodide, within the optimal band gap range for single-junction PVs. However, the difference between lowest indirect and direct transitions increases down the halide group, leaving the lowest direct transition at $1.79 \mathrm{eV}$. A summary of the lowest transitions for all compounds is listed in Table 2. Yu and Zunger have previously highlighted the importance of direct allowed transitions for producing strong absorbance in PV materi$\mathrm{als}^{44,45}$ an indirect band gap need not necessitate weak absorption, provided a direct allowed transition exists only slightly higher in energy. In the case of the $\mathrm{Cs}_{2} \mathrm{AgBiX}_{6}$ materials, however, such a large difference between the two transitions $(>0.5 \mathrm{eV})$ in all three compounds is likely to severely impact strong absorption in the visible range. In the context of solar cells, this will reduce both the photocurrent and photovoltage, leading to poor device performance. Further examination of the valence and conduction band character reveals that an indirect band gap is unavoidable in these materials.

To illustrate this fundamental difference, a " $\mathrm{Cs}_{2} \mathrm{~Pb}_{2} \mathrm{Br}_{6}$ " cubic double perovskite was constructed by replacing the $\mathrm{Ag}$ and $\mathrm{Bi}$ sites with $\mathrm{Pb}$ in the unit cell of $\mathrm{Cs}_{2} \mathrm{AgBiBr}_{6}$ to allow direct comparison between the cesium lead halides and the silverbismuth double perovskites. It should be noted that at room temperature $\mathrm{CsPbBr}_{3}$ actually crystallizes in the orthorhombic space group Pnma, formed by tilting of the $\mathrm{Pb}-\mathrm{Br}$ octahedra in the cubic perovskite, and as such, the band gap is recorded at around $2.2 \mathrm{eV}^{46,47}$ Here, however, we use the double perovskite structure to demonstrate the potential for strong $\mathrm{Pb}-\mathrm{Br}-\mathrm{Pb}$ bonding when the octahedra are in the fully cubic arrangement. The resulting electronic band structure and charge density isosurfaces of the upper valence bands and lower conduction bands are shown in Figure $2 \mathrm{~b}$. $\mathrm{Cs}_{2} \mathrm{~Pb}_{2} \mathrm{Br}_{6}$ possesses a much smaller band gap than $\mathrm{Cs}_{2} \mathrm{AgBiBr}_{6}$, which is due to the significantly wider conduction band in the lead compound that 

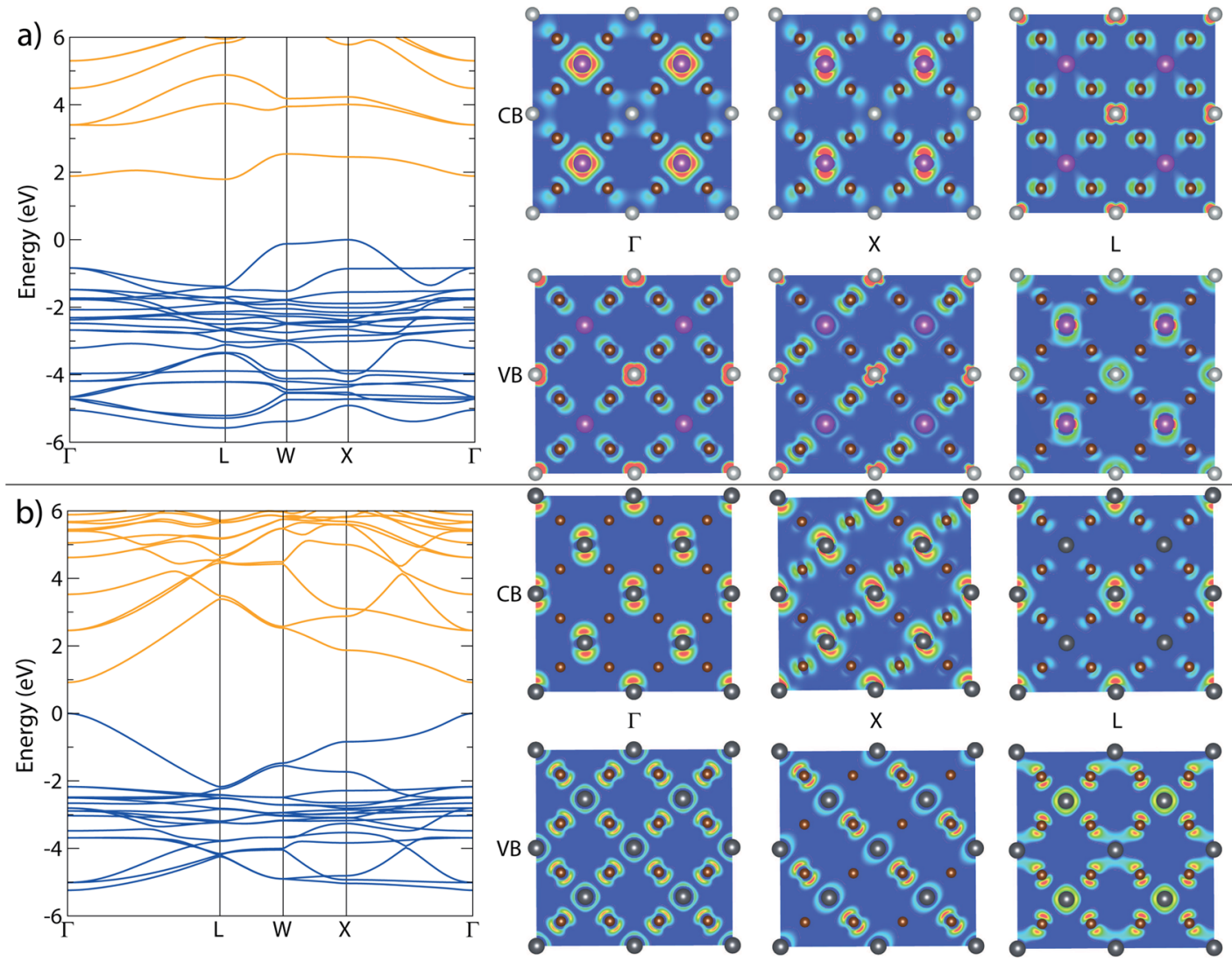

Figure 2. HSE06+SOC band structures of (a) $\mathrm{Cs}_{2} \mathrm{AgBiBr}_{6}$ and (b) "Cs $\mathrm{Pb}_{2} \mathrm{Br}_{6}$ " (CsPbBr 3 in the double perovskite structure), with respective charge density isosurfaces of the VBM and CBM, pictured along (110) of the primitive cell and at specific $k$-points. Silver atoms are in light gray, bismuth is in purple, lead is in dark gray, and bromine is in brown. The VBM is set to $0 \mathrm{eV}$.

Table 2. Lowest Indirect $\left(E_{\mathrm{g}}^{\mathrm{i}}\right)$ and Direct Allowed $\left(E_{\mathrm{g}}^{\mathrm{da}}\right)$ Transitions, with CBWs and Spectroscopic Limited Maximum Efficiencies (SLMEs), Predicted Using HSE06+SOC, of $\mathrm{Cs}_{2} \mathrm{MBiX}_{6}(\mathrm{M}=\mathrm{Ag}, \mathrm{In}, \mathrm{Tl} ; \mathrm{X}=\mathrm{Cl}, \mathrm{Br}, \mathrm{I})$ and $\mathrm{CsPbBr}_{3}$ within the Cubic Double Perovskite Structure (“ $\mathrm{Cs}_{2} \mathrm{~Pb}_{2} \mathrm{Br}_{6}$ ”)

\begin{tabular}{lcccc} 
compound & $E_{\mathrm{g}}^{\mathrm{i}} / \mathrm{eV}$ & $E_{\mathrm{g}}^{\mathrm{da}} / \mathrm{eV}$ & $\mathrm{CBW} / \mathrm{eV}$ & SLME/\% \\
$\mathrm{Cs}_{2} \mathrm{AgBiCl}_{6}$ & 2.35 & 2.87 & 0.58 & 3.90 \\
$\mathrm{Cs}_{2} \mathrm{AgBiBr}_{6}$ & 1.79 & 2.45 & 0.75 & 7.92 \\
$\mathrm{Cs}_{2} \mathrm{AgBiI}_{6}$ & 1.08 & 1.79 & 0.95 & 12.37 \\
${ }^{\mathrm{C}} \mathrm{Cs}_{2} \mathrm{~Pb}_{2} \mathrm{Br}_{6}$ ” & & 0.92 & 2.47 & 17.15 \\
$\mathrm{Cs}_{2} \mathrm{InBiCl}_{6}$ & & 0.28 & 2.17 & 10.25 \\
$\mathrm{Cs}_{2} \mathrm{InBiBr}_{6}$ & & 0.36 & 2.03 & 10.43 \\
$\mathrm{Cs}_{2} \mathrm{TlBiCl}_{6}$ & & 1.28 & 2.24 & 15.87 \\
$\mathrm{Cs}_{2} \mathrm{TlBiBr}_{6}$ & & 0.71 & 2.22 & 17.72 \\
\hline
\end{tabular}

is close to $2.5 \mathrm{eV}$ compared to $0.75 \mathrm{eV}$ in $\mathrm{Cs}_{2} \mathrm{AgBiBr}_{6}$. This conduction bandwidth (CBW) arises from the interaction of neighboring $\mathrm{Pb}$ nonbonding $\mathrm{p}$ orbitals at $\Gamma$ compared to the highly antibonding configuration at $\mathrm{L}$. In $\mathrm{Cs}_{2} \mathrm{AgBiBr}_{6}$, the frontier orbitals are confined to either only silver or bismuth, requiring next-nearest-neighbor cation interactions and, therefore, leading to a more localized, narrow conduction band and a large band gap.

In the valence band of $\mathrm{Cs}_{2} \mathrm{AgBiBr}_{6}$, at $\Gamma$, the band is localized on only the $\mathrm{Ag}$ cations and $\mathrm{Br}$ anions. This is similar to the conduction band, where the band is localized on only $\mathrm{Bi}$ or $\mathrm{Ag}$ cations, and therefore, the band remains relatively flat. Considering $\mathrm{Cs}_{2} \mathrm{~Pb}_{2} \mathrm{Br}_{6}$ in comparison, the $\mathrm{Pb}$ atoms all contribute equally, leading to a stronger interaction and a high $\mathrm{VBM}$ at $\Gamma$. At $\mathrm{X}$, however, the strongly directional interaction of the $\mathrm{Ag} \mathrm{d}_{z}{ }^{2}$ with the bromine atoms is able to incorporate some $\mathrm{Bi}$ s character into the valence band as well, leading to a much higher valence band compared to $\Gamma$. As a result, the band gap of $\mathrm{Cs}_{2} \mathrm{AgBiBr}_{6}$ becomes indirect, enforced by the preferential $\mathrm{Ag} \mathrm{d}$ interactions at $\mathrm{X}$. As these features are replicated in the chloride and iodide, it appears that the electronic mismatch between $\mathrm{Ag}$ and $\mathrm{Bi}$ is the fundamental cause of the large, indirect band gaps of the $\mathrm{Cs}_{2} \mathrm{AgBiX}_{6}$ family.

In order to permit a direct band gap in a lead-free double perovskite, silver must be replaced by an atom with valence $s$ states, for example, the "lone pair" 5s and 6s states in $\mathrm{In}^{+}$and $\mathrm{Tl}^{+}$. To test this, we have computationally examined "hypothetical" chloride and bromide double perovskites containing $\mathrm{Tl}$ and $\mathrm{In}$ in place of $\mathrm{Ag}$, for example, $\mathrm{Cs}_{2} \mathrm{TlBiBr}_{6}$. By replacing $\mathrm{Ag}$ with a valence $n \mathrm{~s}^{2}$ cation, these s states are able to mix with the Bi s and anion states, creating a direct allowed transition at $\Gamma$, as seen in the proposed band structure for the hypothetical $\mathrm{Cs}_{2} \mathrm{TlBiBr}_{6}$ in Figure 3. Notably, it is evident that the inclusion of $\mathrm{Tl}$ enables the replication of many of the band features of the " $\mathrm{Cs}_{2} \mathrm{~Pb}_{2} \mathrm{Br}_{6}$ " structure, including the wider conduction band and high valence band at $\Gamma$ as a result of the complementary contributions of both $\mathrm{Bi}$ and $\mathrm{Tl}$. Unlike the $\mathrm{d}$ orbitals of $\mathrm{Ag}$, the $\mathrm{s}$ contribution from $\mathrm{Tl}$ matches the $\mathrm{Bi}$ s contribution, in analogy to the $\mathrm{Pb} s$ in $\mathrm{Cs}_{2} \mathrm{~Pb}_{2} \mathrm{Br}_{6}$, leading to a completely symmetric interaction with the bromine atoms. However, the introduction of these levels does lead to a narrowing of the band gap, particularly with In; this may be due to the higher-energy $5 \mathrm{~s}$ states in In, compared to $\mathrm{Bi} 6 \mathrm{~s}$. This leads to only $\mathrm{Cs}_{2} \mathrm{TlBiCl}_{6}$ 

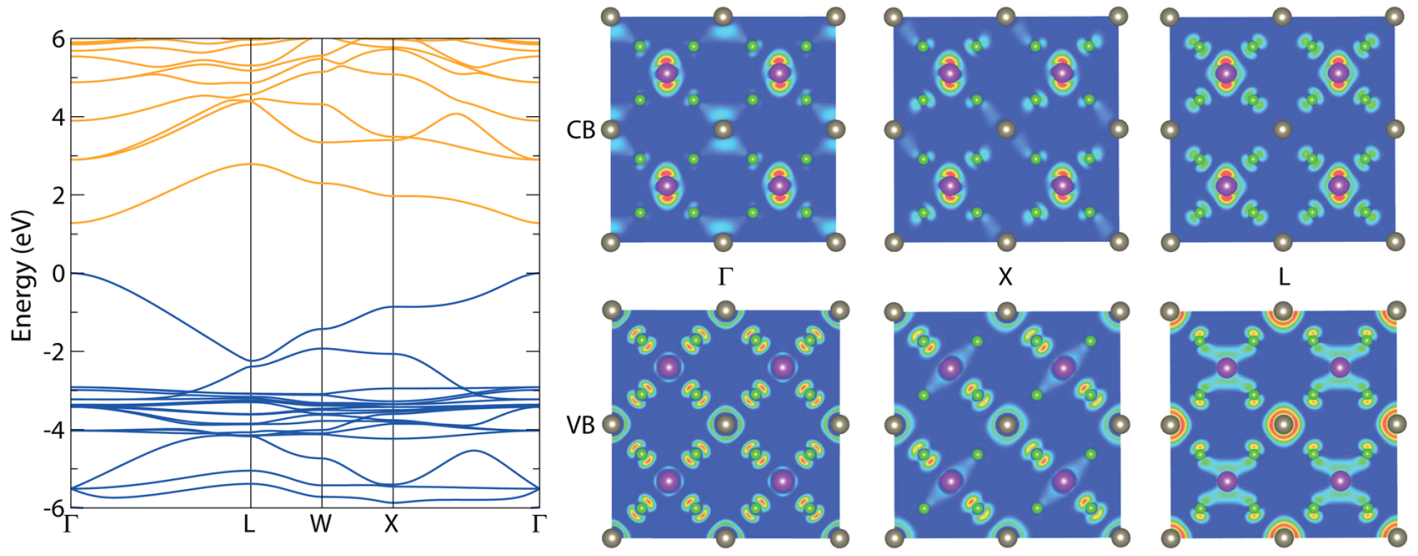

Figure 3. HSE06+SOC band structure of $\mathrm{Cs}_{2} \mathrm{TlBiCl}_{6}$, with respective charge density isosurfaces of VBM and CBM at specific $k$-points and pictured along (110) of the primitive cell. Thallium atoms are in gray, bismuth is in purple, and chlorine is in green. The VBM is set to 0 eV.

possessing an optimal band gap for PV applications; yet including $\mathrm{Tl}$ will reintroduce problems of toxicity, one of the primary reasons for replacing lead. Alternatively, as Volonakis et al. propose, introducing methylammonium in place of the cesium could break the symmetry restriction on the direct transition at $\Gamma$.

To investigate the possibility of methylammonium substitution and its potential effect on the electronic structure, two structures were tried and calculated. The first is $\left(\mathrm{CH}_{3} \mathrm{NH}_{3}\right)_{2} \mathrm{AgBiI}_{6}$, the iodide analogue of the $\left(\mathrm{CH}_{3} \mathrm{NH}_{3}\right)_{2} \mathrm{AgBiCl}_{6}$ calculated by Volonakis et al., ${ }^{39}$ constructed by taking the orthorhombic structure of $\left(\mathrm{CH}_{3} \mathrm{NH}_{3}\right)$ $\mathrm{PbI}_{3}$ with $\mathrm{Pb}$ replaced alternatively with $\mathrm{Ag}$ and $\mathrm{Bi}$. For the second, the methylammonium cation was introduced into the $\mathrm{Cs}_{2} \mathrm{AgBiBr}_{6}$ primitive cell, in place of cesium, and the structure was relaxed with the PBEsol functional. In the HSE06+SOC band structure of " $\left(\mathrm{CH}_{3} \mathrm{NH}_{3}\right)_{2} \mathrm{AgBiI}_{6}$ ", the symmetry lowers from $\mathrm{Pnma}$ in $\left(\mathrm{CH}_{3} \mathrm{NH}_{3}\right) \mathrm{PbI}_{3}$ to $\mathrm{C} 2 / m$ as a result of the $\mathrm{Ag} / \mathrm{Bi}$ substitution (Figure $3 \mathrm{~b}$ in the Supporting Information). In contrast to the results of Volonakis et al., the calculated fundamental band gap of $1.38 \mathrm{eV}$ is indirect, with the VBM at $\mathrm{A}_{0}$ and $\mathrm{CBM}$ at $\mathrm{D}$, although the direct transition at $\Gamma$ of $1.59 \mathrm{eV}$ is fully symmetry-allowed. On the other hand, the band structure of " $\left(\mathrm{CH}_{3} \mathrm{NH}_{3}\right)_{2} \mathrm{AgBiBr}_{6}$ ", based on the cubic double perovskite structure, gives a substantially indirect band gap of $1.75 \mathrm{eV}$, with the lowest available direct transition at $2.40 \mathrm{eV}$ (Figure 4 in the Supporting Information). Using the special cubic $k$-points from $\mathrm{Cs}_{2} \mathrm{AgBiBr}_{6}$ demonstrates that while the methylammonium substitution lowers the degeneracy of many of the bands, the effect on the band edges and band gap is minimal (the VBM changes from $\mathrm{X}$ to $\mathrm{W}$ ). The electronic structure changes induced by methylammonium incorporation are unlikely to enhance the PV performance; however, it is possible that a distinct crystal structure with different properties may be adopted for this composition.

The spectroscopic limited maximum efficiency (SLME) is a metric proposed by $\mathrm{Yu}$ and Zunger that includes the strength of optical absorption and the nature of the band gap in the overall theoretical efficiency of an absorber material. ${ }^{44}$ The SLME approach thus improves upon using the magnitude of the band gap alone as an assessment of PV performance and has been very useful in identifying and analyzing potential new PV absorbers in previous studies. ${ }^{45,48,49}$ Thus, to quantify the effect of the large difference between the indirect and direct band gaps of these materials on the potential PV performance of the
$\mathrm{Cs}_{2} \mathrm{AgBiX}$ family, we present the SLMEs for all of the materials discussed in Table 2. The SLMEs are calculated using a suitable film thickness of $L=200 \mathrm{~nm}$. The large, indirect nature of the band gaps of the $\mathrm{Cs}_{2} \mathrm{AgBiX}_{6}$ series impacts their SLME considerably, especially the chloride and bromide, which are below 10\%; in comparison, the SLME of the champion absorber $\mathrm{CuInSe}_{2}$ is $\sim 23 \%{ }^{45}$ On the other hand, the hypothetical $\mathrm{Cs}_{2} \mathrm{TlBiCl}_{6}$ and " $\mathrm{Cs}_{2} \mathrm{~Pb}_{2} \mathrm{Br}_{6}$ " possess SLMEs of around $17 \%$, despite their small, but direct, band gaps.

As highlighted above, poor stability is one of the major reasons to look beyond the methylammonium lead halides for emerging PV absorbers. In order to assess the stability of these compounds, the energies of the competing phases of $\mathrm{Cs}_{2} \mathrm{AgBiX}_{6}$ were obtained using PBEsol. The energies of the double perovskites were then compared to the competing phases using the program $\mathrm{CPLAP}^{50}$ to determine their thermodynamic stability. As a result, $\mathrm{Cs}_{2} \mathrm{AgBiCl}_{6}$ and $\mathrm{Cs}_{2} \mathrm{AgBiBr}_{6}$ were found to be stable with respect to decomposition; the latter is supported by the lack of mass loss in the thermogravimetric traces of Slavney et al. up to 430 ${ }^{\circ} \mathrm{C}$, well above the decomposition of MAPI and the likely operating range. ${ }^{37} \mathrm{Cs}_{2} \mathrm{AgBiI}_{6}$, however, was found to be thermodynamically unstable; in particular, further investigation demonstrated that it is unstable when considering the decomposition path in eq 1 , with $\Delta H_{\mathrm{r}}=-0.41 \mathrm{eV}$ per formula unit.

$$
2 \mathrm{Cs}_{2} \mathrm{AgBiX}_{6} \stackrel{\Delta H_{\mathrm{r}}}{\longrightarrow} \mathrm{Cs}_{3} \mathrm{Bi}_{2} \mathrm{X}_{9}+2 \mathrm{AgX}+\mathrm{CsX}
$$

This is similar to recent findings that MAPI is intrinsically unstable with respect to its constituent iodides ${ }^{13,14}$ and indicates that even if it is possible to synthesize $\mathrm{Cs}_{2} \mathrm{AgBiI}_{6}$, it may still suffer from instability issues in devices. Additionally, the proposed structures for most of the indium and thallium double perovskites were also unstable with respect to their relative halides, as reported in Table 3 . As such, while the silver-bismuth chloride and bromide double perovskites demonstrate improved stability compared to their methylammonium lead counterparts, moving to iodide-based systems in particular leads to instability with respect to the $\mathrm{M}_{3} \mathrm{Bi}_{2} \mathrm{I}_{9}$ (M $=\mathrm{Cs}, \mathrm{CH}_{3} \mathrm{NH}_{3}$ ) competing phases, which have also been examined for PV applications, ${ }^{51,52}$ as does introducing other $n \mathrm{~s}^{2}$ cations on the $\mathrm{Ag}$ site.

Moving to the double perovskite motif also introduces the possibility of disorder; with $\mathrm{Ag}^{+}$and $\mathrm{Bi}^{3+}$ occupying similar 
Table 3. Decomposition Energies of the Double Perovskites Using the Pathway in Equation 1

\begin{tabular}{lc}
\multicolumn{1}{c}{ compound } & $\Delta H_{\mathrm{r}} / \mathrm{eV}$ \\
$\mathrm{Cs}_{2} \mathrm{AgBiCl}_{6}$ & +0.57 \\
$\mathrm{Cs}_{2} \mathrm{AgBiBr}_{6}$ & +0.38 \\
$\mathrm{Cs}_{2} \mathrm{AgBiI}_{6}$ & -0.41 \\
$(\mathrm{MA})_{2} \mathrm{AgBiI}_{6}$ & -0.10 \\
$\mathrm{Cs}_{2} \mathrm{InBiCl}_{6}$ & +0.01 \\
$\mathrm{Cs}_{2} \mathrm{InBiBr}_{6}$ & -0.04 \\
$\mathrm{Cs}_{2} \mathrm{TlBiCl}_{6}$ & -0.05 \\
$\mathrm{Cs}_{2} \mathrm{TlBiBr}_{6}$ & -0.21 \\
\hline
\end{tabular}

environments within the lattice, disorder on the cation sites is a possibility. Given the observed impact of cation disorder on the band gap and potentially a $V_{\text {oc }}$ deficit, in other solar absorbers like $\mathrm{Cu}_{2} \mathrm{ZnSnS}_{4}, \mathrm{ZnSnN}_{2}$, and $\mathrm{ZnSnP}_{2}$, ${ }^{53-56}$ high levels of disorder could significantly influence the performance of these materials. To investigate this, $3 \times 3 \times 3$ primitive supercells (270 atoms) were constructed of the fully ordered $\mathrm{Cs}_{2} \mathrm{AgBiBr}_{6}$ perovskite and a "special quasirandom structure" (SQS), 57,58 representing maximal disorder; these cells were then relaxed and their relative energies at equilibrium obtained. The ordered perovskite is lower in energy, in line with McClure et al.'s observation that Rietveld refinement of $\mathrm{Cs}_{2} \mathrm{AgBiBr}_{6}$ was not improved by introducing cation disorder, ${ }^{38}$ with a difference in energy of $29 \mathrm{meV} /$ atom between the two supercells. In a simple regular solution model, however, this relatively small energy gap means that entropic contribution from disorder will outweigh the enthalpic difference at a potential order/disorder transition temperature of $477 \mathrm{~K}$. This is sufficiently low that synthesis temperature may affect different samples, particularly annealed thin films. The band gaps of the two structures were also calculated using PBEsol+SOC in order to assess the effect of disorder on the electronic structure. The transition at $\Gamma$ in the disordered supercell was found to be $0.256 \mathrm{eV}$, much smaller than $1.504 \mathrm{eV}$ in the ordered supercell. From this, we might expect that, should samples possess different degrees of cation disorder, this could significantly alter the band gap measured and therefore may partly explain the variance in measured band gaps for the silver-bismuth double perovskites.

In this Letter, we have investigated the $\mathrm{Cs}_{2} \mathrm{AgBiX}_{6}$ double perovskite family using GGA and hybrid DFT in order to thoroughly assess their electronic structure and stability, gaining insight into their suitability as nontoxic replacements to the methylammonium lead halides. Careful investigation of their orbital makeup reveals that the fundamental mismatch of $\mathrm{Ag} \mathrm{d}$ and $\mathrm{Bi}$ s orbitals at the band edges leads to an inherently indirect, large band gap due to a reduced CBW. Hypothetical replacement of $\mathrm{Ag}$ by $n \mathrm{~s}^{2}$ ions such as $\mathrm{Tl}^{+}$, however, demonstrates that the $s-s$ nearest-neighbor cation interactions restore the direct band gap. As a consequence of the highly indirect band gaps, the SLME of the silver-bismuth double perovskites is low. Additionally, we have predicted the thermodynamic stability of these compounds; while $\mathrm{Cs}_{2} \mathrm{AgBiCl}_{6}$ and $\mathrm{Cs}_{2} \mathrm{AgBiBr}_{6}$ are stable, the majority of the other structures are unstable with respect to their ternary and binary constituent iodides. Finally, the effect of $\mathrm{Ag} / \mathrm{Bi}$ cation disorder on the band gap was found to be significant, but disorder is only predicted to be accessible at high temperature. As a result, we present a number of inherent limitations of the $\mathrm{Cs}_{2} \mathrm{AgBiX}_{6}$ family as solar absorbers and as potential replacements of the methylammonium lead halides. In order to fully access the same exceptional properties of the methylammonium lead halides, future syntheses may require the matching of $n s^{2}$ cations and possibly moving beyond the cubic double perovskite structure.

\section{THEORETICAL METHODS}

All calculations were performed using DFT within periodic boundary conditions through the Vienna Ab Initio Simulation Package (VASP).${ }^{59-62}$ For geometry optimizations and stability field calculations, the PBEsol functional was used, ${ }^{63}$ while for band structure and optical calculations, the screened hybrid functional HSE06 was used, ${ }^{64}$ with the addition of spin-orbit effects (HSE06+SOC). HSE06 incorporates 25\% HartreeFock exchange with a screening parameter of $\omega=0.11 \mathrm{bohr}^{-1}$ in addition to $75 \%$ exchange and correlation from the Generalized Gradient Approximation (GGA) functional PBE. ${ }^{65}$ Scalar-relativistic pseudopotentials were used, and the projector-augmented wave method was used to describe the interaction between core and valence electrons. ${ }^{66}$ The optical response was calculated using the method of Furthmüller et al. to obtain the high-frequency real and imaginary dielectric functions. ${ }^{67}$ This allowed the calculation of SLMEs using the method of $\mathrm{Yu}$ and Zunger. ${ }^{44} \mathrm{~A} 3 \times 3 \times 3 \Gamma$-centered $k$-mesh and a $400 \mathrm{eV}$ plane-wave cutoff were used for all electronic structure calculations, while a tighter $k$-mesh of $4 \times 4 \times 4$ was used for the optical calculations. A convergence criterion of $0.01 \mathrm{eV} \AA^{-1}$ was used on the forces on each atom during optimization. The equilibrium structures of the compounds studied in this report are provided in an online repository: https://github.com/SMTG-UCL/AgBi_double_perovskite.

\section{ASSOCIATED CONTENT}

\section{Supporting Information}

The Supporting Information is available free of charge on the ACS Publications website at DOI: 10.1021/acsenergylett.6b00471.

HSE06+SOC electronic band structures for all compounds studied and SLME versus thickness for $\mathrm{Cs}_{2} \mathrm{AgBiX}_{6}(\mathrm{X}=\mathrm{Cl}, \mathrm{Br}, \mathrm{I})(\mathrm{PDF})$

\section{AUTHOR INFORMATION}

\section{Corresponding Author}

*E-mail: d.scanlon@ucl.ac.uk.

\section{Notes}

The authors declare no competing financial interest.

\section{ACKNOWLEDGMENTS}

The work presented in this Letter was performed on the ARCHER UK National Supercomputing Service, via our membership of the UK's HEC Materials Chemistry Consortium, funded by EPSRC (EP/L000202). C.N.S. is grateful to the Department of Chemistry at UCL for the provision of a DTA studentship. D.O.S. acknowledges support from the SUPERSOLAR Solar Energy Hub (EP/J017361/1) and EP/ N01572X/1. The work at Bath was supported by the ERC (Grant No. 277757) and the EPSRC (Grant No. EP/K016288/ 1, EP/L017792/1, and EP/M009580/1). A.W. and D.O.S. acknowledge membership of the Materials Design Network. 


\section{REFERENCES}

(1) Kojima, A.; Teshima, K.; Shirai, Y.; Miyasaka, T. Organo Metal Halide Perovskites as Visible-Light Sensitizer for Photovoltaic Cells. J. Am. Chem. Soc. 2009, 131, 6050-6051.

(2) Saliba, M.; Matsui, T.; Seo, J.-Y.; Domanski, K.; Correa-Baena, J.P.; Nazeeruddin, M. K.; Zakeeruddin, S. M.; Tress, W.; Abate, A.; Hagfeldt, A.; et al. Cesium-containing triple cation perovskite solar cells: improved stability, reproducibility and high efficiency. Energy Environ. Sci. 2016, 9, 1989-1997.

(3) Saliba, M.; Orlandi, S.; Matsui, T.; Aghazada, S.; Cavazzini, M.; Correa-Baena, J.-P.; Gao, P.; Scopelliti, R.; Mosconi, E.; Dahmen, K.$\mathrm{H}$.; et al. A molecularly engineered hole-transporting material for efficient perovskite solar cells. Nat. Energy 2016, 1, 15017.

(4) Brenner, T. M.; Egger, D. A.; Kronik, L.; Hodes, G.; Cahen, D. Hybrid organic-inorganic perovskites: low-cost semiconductors with intriguing charge-transport properties. Nat. Rev. Mater. 2016, 1, 15007. (5) Barrows, A. T.; Pearson, A. J.; Kwak, C. K.; Dunbar, A. D. F.; Buckley, A. R.; Lidzey, D. G. Efficient Planar Heterojunction Mixedhalide Perovskite Solar Cells Deposited Via Spray-Deposition. Energy Environ. Sci. 2014, 7, 2944.

(6) Malinkiewicz, O.; Yella, A.; Lee, Y. H.; Espallargas, G. M.; Graetzel, M.; Nazeeruddin, M. K.; Bolink, H. J. Perovskite solar cells employing organic charge-transport layers. Nat. Photonics 2013, 8, $128-132$.

(7) Bhachu, D. S.; Scanlon, D. O.; Saban, E. J.; Bronstein, H.; Parkin, I. P.; Carmalt, C. J.; Palgrave, R. G. Scalable route to $\mathrm{CH}_{3} \mathrm{NH}_{3} \mathrm{PbI}_{3}$ perovskite thin films by aerosol assisted chemical vapour deposition. $J$. Mater. Chem. A 2015, 3, 9071-9073.

(8) De Wolf, S.; Holovsky, J.; Moon, S.-J.; Löper, P.; Niesen, B.; Ledinsky, M.; Haug, F.-J.; Yum, J.-H.; Ballif, C. Organometallic halide perovskites: sharp optical absorption edge and its relation to photovoltaic performance. J. Phys. Chem. Lett. 2014, 5, 1035-1039.

(9) Stranks, S. D.; Eperon, G. E.; Grancini, G.; Menelaou, C.; Alcocer, M. J. P.; Leijtens, T.; Herz, L. M.; Petrozza, A.; Snaith, H. J. Electron-Hole Diffusion Lengths Exceeding 1 Micrometer in an Organometal Trihalide Perovskite Absorber. Science 2013, 342, 341344.

(10) Wehrenfennig, C.; Eperon, G. E.; Johnston, M. B.; Snaith, H. J.; Herz, L. M. High Charge Carrier Mobilities and Lifetimes in Organolead Trihalide Perovskites. Adv. Mater. 2014, 26, 1584-1589.

(11) Brandt, R. E.; Stevanović, V.; Ginley, D. S.; Buonassisi, T. Identifying defect-tolerant semiconductors with high minority carrier lifetimes: Beyond hybrid lead halide perovskites. MRS Commun. 2015, $5,265-275$

(12) Walsh, A.; Scanlon, D. O.; Chen, S.; Gong, X. G.; Wei, S.-H. Self-Regulation Mechanism for Charged Point Defects in Hybrid Halide Perovskites. Angew. Chem., Int. Ed. 2015, 54, 1791-1794.

(13) Zhang, Y.-Y.; Chen, S.; Xu, P.; Xiang, H.; Gong, X.-G.; Walsh, A.; Wei, S.-H. Intrinsic Instability of the Hybrid Halide Perovskite Semiconductor $\mathrm{CH}_{3} \mathrm{NH}_{3} \mathrm{PbI}_{3}$. arXiv:1506.01301 [cond-mat.mtrl-sci] 2015.

(14) Nagabhushana, G. P.; Shivaramaiah, R.; Navrotsky, A. Direct calorimetric verification of thermodynamic instability of lead halide hybrid perovskites. Proc. Natl. Acad. Sci. U. S. A. 2016, 113, 77177721.

(15) Aristidou, N.; Sanchez-Molina, I.; Chotchuangchutchaval, T.; Brown, M.; Martinez, L.; Rath, T.; Haque, S. A. The Role of Oxygen in the Degradation of Methylammonium Lead Trihalide Perovskite Photoactive Layers. Angew. Chem., Int. Ed. 2015, 54, 8208-8212.

(16) Bryant, D.; Aristidou, N.; Pont, S.; Sanchez-Molina, I.; Chotchunangatchaval, T.; Wheeler, S.; Durrant, J. R.; Haque, S. A. Light and oxygen induced degradation limits the operational stability of methylammonium lead triiodide perovskite solar cells. Energy Environ. Sci. 2016, 9, 1655-1660.

(17) Babayigit, A.; Ethirajan, A.; Muller, M.; Conings, B. Toxicity of organometal halide perovskite solar cells. Nat. Mater. 2016, 15, 247251.

(18) Ganose, A. M.; Savory, C. N.; Scanlon, D. O. Beyond methylammonium lead iodide: prospects for the emergent field of $n s^{2}$ containing solar absorbers. Chem. Commun. 2016, DOI: 10.1039/ C6CC06475B.

(19) McMeekin, D. P.; Sadoughi, G.; Rehman, W.; Eperon, G. E.; Saliba, M.; Hörantner, M. T.; Haghighirad, A.; Sakai, N.; Korte, L.; Rech, B.; et al. A mixed-cation lead mixed-halide perovskite absorber for tandem solar cells. Science 2016, 351, 151-155.

(20) Beal, R. E.; Slotcavage, D. J.; Leijtens, T.; Bowring, A. R.; Belisle, R. A.; Nguyen, W. H.; Burkhard, G. F.; Hoke, E. T.; McGehee, M. D. Cesium Lead Halide Perovskites with Improved Stability for Tandem Solar Cells. J. Phys. Chem. Lett. 2016, 7, 746-751.

(21) Ganose, A. M.; Savory, C. N.; Scanlon, D. O. $\left(\mathrm{CH}_{3} \mathrm{NH}_{3}\right)_{2} \mathrm{~Pb}-$ $(\mathrm{SCN})_{2} \mathrm{I}_{2}$ : A More Stable Structural Motif for Hybrid Halide Photovoltaics? J. Phys. Chem. Lett. 2015, 6, 4594-4598.

(22) Chen, B.; Shi, J.; Zheng, X.; Zhou, Y.; Zhu, K.; Priya, S. Ferroelectric solar cells based on inorganic-organic hybrid perovskite. J. Mater. Chem. A 2015, 3, 7699-7705.

(23) Jiang, Q.; Rebollar, D.; Gong, J.; Piacentino, E. L.; Zheng, C.; $\mathrm{Xu}, \mathrm{T}$. Pseudohalide-Induced Moisture Tolerance in Perovskite $\mathrm{CH}_{3} \mathrm{NH}_{3} \mathrm{~Pb}(\mathrm{SCN})_{2} \mathrm{I}$ Thin Films. Angew. Chem., Int. Ed. 2015, 54, $7617-7620$.

(24) Smith, I. C.; Hoke, E. T.; Solis-Ibarra, D.; McGehee, M. D.; Karunadasa, H. I. A Layered Hybrid Perovskite Solar-Cell Absorber with Enhanced Moisture Stability. Angew. Chem., Int. Ed. 2014, 53, 11232-11235.

(25) Cao, D. H.; Stoumpos, C. C.; Farha, O. K.; Hupp, J. T.; Kanatzidis, M. G. 2D Homologous Perovskites as Light-Absorbing Materials for Solar Cell Applications. J. Am. Chem. Soc. 2015, 137, $7843-7850$

(26) Quan, L. N.; Yuan, M.; Comin, R.; Voznyy, O.; Beauregard, E. M.; Hoogland, S.; Buin, A.; Kirmani, A. R.; Zhao, K.; Amassian, A.; et al. Ligand-Stabilized Reduced-Dimensionality Perovskites. J. Am. Chem. Soc. 2016, 138, 2649-2655.

(27) Maughan, A. E.; Kurzman, J. A.; Neilson, J. R. Hybrid InorganicOrganic Materials with an Optoelectronically Active Aromatic Cation: $\left(\mathrm{C}_{7} \mathrm{H}_{7}\right)_{2} \mathrm{SnI}_{6}$ and $\mathrm{C}_{7} \mathrm{H}_{7} \mathrm{PbI}_{3}$. Inorg. Chem. 2015, 54, 370-378.

(28) Liu, J.-J.; Guan, Y.-F.; Jiao, C.; Lin, M.-J.; Huang, C.-C.; Dai, W. A Panchromatic Hybrid Crystal of Iodoplumbate Nanowires and Jaggregated Naphthalene Diimides with Long-lived Charge-separated States. Dalton Trans. 2015, 44, 5957-5960.

(29) Savory, C. N.; Palgrave, R. G.; Bronstein, H.; Scanlon, D. O. Spatial Electron-hole Separation in a One Dimensional Hybrid Organic-Inorganic Lead Iodide. Sci. Rep. 2016, 6, 20626.

(30) Yang, R. X.; Butler, K. T.; Walsh, A. Assessment of Hybrid Organic-Inorganic Antimony Sulfides for Earth-Abundant Photovoltaic Applications. J. Phys. Chem. Lett. 2015, 6, 5009-5014.

(31) Travis, W.; Knapp, C. E.; Savory, C. N.; Ganose, A. M.; Kafourou, P.; Song, X.; Sharif, Z.; Cockcroft, J. K.; Scanlon, D. O.; Bronstein, H.; et al. Hybrid Organic-Inorganic Coordination Complexes as Tunable Optical Response Materials. Inorg. Chem. 2016, 55, 3393-3400.

(32) Fabian, D. M.; Ardo, S. Hybrid organic-inorganic solar cells based on bismuth iodide and 1,6-hexanediammonium dication. J. Mater. Chem. A 2016, 4, 6837-6841.

(33) Bass, K. K.; Estergreen, L.; Savory, C. N.; Buckeridge, J.; Scanlon, D. O.; Djurovich, P. I.; Bradforth, S. E.; Thompson, M. E.; Melot, B. C. Vibronic Structure in Room Temperature Photoluminescence of the Halide Perovskite $\mathrm{Cs}_{3} \mathrm{Bi}_{2} \mathrm{Br}_{9}$. Inorg. Chem. 2016, DOI: 10.1021/acs.inorgchem.6b01571.

(34) Morrs, L. R.; Robinson, W. R. Crystal structure of $\mathrm{Cs}_{2} \mathrm{NaBiCl}_{6}$ Acta Crystallogr., Sect. B: Struct. Crystallogr. Cryst. Chem. 1972, 28, 653-654.

(35) Pelle, F.; Jacquier, B.; Denis, J.; Blanzat, B. Optical properties of $\mathrm{Cs}_{2} \mathrm{NaBiCl}_{6}$. J. Lumin. 1978, 17, 61-72.

(36) Smit, W.; Dirksen, G.; Stufkens, D. Infrared and Raman spectra of the elpasolites $\mathrm{Cs}_{2} \mathrm{NaSbCl}_{6}$ and $\mathrm{Cs}_{2} \mathrm{NaBiCl}_{6}$ : Evidence for a pseudo Jahn-Teller distorted ground state. J. Phys. Chem. Solids 1990, 51, 189196.

(37) Slavney, A. H.; Hu, T.; Lindenberg, A. M.; Karunadasa, H. I. A Bismuth-Halide Double Perovskite with Long Carrier Recombination 
Lifetime for Photovoltaic Applications. J. Am. Chem. Soc. 2016, 138, 2138-2141.

(38) McClure, E. T.; Ball, M. R.; Windl, W.; Woodward, P. M. $\mathrm{Cs}_{2} \mathrm{AgBiX}_{6}(\mathrm{X}=\mathrm{Br}, \mathrm{Cl})$ : New Visible Light Absorbing, Lead-Free Halide Perovskite Semiconductors. Chem. Mater. 2016, 28, 13481354.

(39) Volonakis, G.; Filip, M. R; Haghighirad, A. A.; Sakai, N.; Wenger, B.; Snaith, H. J.; Giustino, F. Lead-Free Halide Double Perovskites via Heterovalent Substitution of Noble Metals. J. Phys. Chem. Lett. 2016, 7, 1254-1259.

(40) Wei, F.; Deng, Z.; Sun, S.; Xie, F.; Kieslich, G.; Evans, D. M.; Carpenter, M. A.; Bristowe, P. D.; Cheetham, A. K. The synthesis, structure and electronic properties of a lead-free hybrid inorganicorganic double perovskite $(\mathrm{MA})_{2} \mathrm{KBiCl}_{6}(\mathrm{MA}=$ methylammonium $)$. Mater. Horiz. 2016, 3, 328-332.

(41) Deng, Z.; Wei, F.; Sun, S.; Kieslich, G.; Cheetham, A. K.; Bristowe, P. D. Exploring the properties of lead-free hybrid double perovskites using a combined computational-experimental approach. J. Mater. Chem. A 2016, 4, 12025-12029.

(42) Filip, M. R.; Hillman, S.; Haghighirad, A. A.; Snaith, H. J.; Giustino, F. Band Gaps of the Lead-Free Halide Double Perovskites $\mathrm{Cs}_{2} \mathrm{BiAgCl}_{6}$ and $\mathrm{Cs}_{2} \mathrm{BiAgBr}_{6}$ from Theory and Experiment. J. Phys. Chem. Lett. 2016, 7, 2579-2585.

(43) Xiao, Z.; Meng, W.; Wang, J.; Yan, Y. Thermodynamic Stability and Defect Chemistry of Bismuth-Based Lead-Free Double Perovskites. ChemSusChem 2016, 9, 2628-2633.

(44) Yu, L.; Zunger, A. Identification of Potential Photovoltaic Absorbers Based on First-Principles Spectroscopic Screening of Materials. Phys. Rev. Lett. 2012, 108, 068701.

(45) Yu, L.; Kokenyesi, R. S.; Keszler, D. A.; Zunger, A. Inverse Design of High Absorption Thin-Film Photovoltaic Materials. Adv. Energy Mater. 2013, 3, 43-48.

(46) Stoumpos, C. C.; Malliakas, C. D.; Peters, J. A.; Liu, Z.; Sebastian, M.; Im, J.; Chasapis, T. C.; Wibowo, A. C.; Chung, D. Y.; Freeman, A. J.; et al. Crystal Growth of the Perovskite Semiconductor $\mathrm{CsPbBr}_{3}$ : A New Material for High-Energy Radiation Detection. Cryst. Growth Des. 2013, 13, 2722-2727.

(47) Kulbak, M.; Cahen, D.; Hodes, G. How Important Is the Organic Part of Lead Halide Perovskite Photovoltaic Cells? Efficient CsPbBr3 Cells. J. Phys. Chem. Lett. 2015, 6, 2452-2456.

(48) Yokoyama, T.; Oba, F.; Seko, A.; Hayashi, H.; Nose, Y.; Tanaka, I. Theoretical Photovoltaic Conversion Efficiencies of $\mathrm{ZnSnP}_{2}$, $\mathrm{CdSnP}{ }_{2}$, and $\mathrm{Zn}_{1-x} \mathrm{Cd}_{x} \mathrm{SnP}_{2}$ Alloys. Appl. Phys. Express 2013, 6, 061201 .

(49) Savory, C. N.; Ganose, A. M.; Travis, W.; Atri, R. S.; Palgrave, R. G.; Scanlon, D. O. An assessment of silver copper sulfides for photovoltaic applications: theoretical and experimental insights. $J$. Mater. Chem. A 2016, 4, 12648-12657.

(50) Buckeridge, J.; Scanlon, D.; Walsh, A.; Catlow, C. Automated procedure to determine the thermodynamic stability of a material and the range of chemical potentials necessary for its formation relative to competing phases and compounds. Comput. Phys. Commun. 2014, 185, 330-338.

(51) Lehner, A. J.; Fabini, D. H.; Evans, H. A.; Hébert, C.-A.; Smock, S. R.; Hu, J.; Wang, H.; Zwanziger, J. W.; Chabinyc, M. L.; Seshadri, R. Crystal and Electronic Structures of Complex Bismuth Iodides $\mathrm{A}_{3} \mathrm{Bi}_{2} \mathrm{I}_{9}$ $(\mathrm{A}=\mathrm{K}, \mathrm{Rb}, \mathrm{Cs})$ Related to Perovskite: Aiding the Rational Design of Photovoltaics. Chem. Mater. 2015, 27, 7137-7148.

(52) Park, B.-W.; Philippe, B.; Zhang, X.; Rensmo, H.; Boschloo, G.; Johansson, E. M. J. Bismuth Based Hybrid Perovskites $\mathrm{A}_{3} \mathrm{Bi}_{2} \mathrm{I}_{9}$ (A: Methylammonium or Cesium) for Solar Cell Application. Adv. Mater. 2015, 27, 6806-6813.

(53) Feldberg, N.; Aldous, J. D.; Linhart, W. M.; Phillips, L. J.; Durose, K.; Stampe, P. A.; Kennedy, R. J.; Scanlon, D. O.; Vardar, G.; Field, R. L.; et al. Growth, disorder, and physical properties of $\mathrm{ZnSnN}_{2}$. Appl. Phys. Lett. 2013, 103, 042109.

(54) Veal, T. D.; Feldberg, N.; Quackenbush, N. F.; Linhart, W. M.; Scanlon, D. O.; Piper, L. F. J.; Durbin, S. M. Band Gap Dependence on Cation Disorder in $\mathrm{ZnSnN}_{2}$ Solar Absorber. Adv. Energy Mater. 2015, 5, 1501462.

(55) Chen, S.; Walsh, A.; Yang, J.-H.; Gong, X. G.; Sun, L.; Yang, P.X.; Chu, J.-H.; Wei, S.-H. Compositional dependence of structural and electronic properties of $\mathrm{Cu}_{2} \mathrm{ZnSn}(\mathrm{S}, \mathrm{Se})_{4}$ alloys for thin film solar cells. Phys. Rev. B: Condens. Matter Mater. Phys. 2011, 83, 125201.

(56) Scanlon, D. O.; Walsh, A. Bandgap engineering of $\mathrm{ZnSnP}_{2}$ for high-efficiency solar cells. Appl. Phys. Lett. 2012, 100, 251911.

(57) Wei, S.-H.; Ferreira, L. G.; Bernard, J. E.; Zunger, A. Electronic properties of random alloys: Special quasirandom structures. Phys. Rev. B: Condens. Matter Mater. Phys. 1990, 42, 9622-9649.

(58) Zunger, A.; Wei, S.-H.; Ferreira, L. G.; Bernard, J. E. Special quasirandom structures. Phys. Rev. Lett. 1990, 65, 353-356.

(59) Kresse, G.; Hafner, J. Ab initio molecular dynamics for liquid metals. Phys. Rev. B: Condens. Matter Mater. Phys. 1993, 47, 558-561.

(60) Kresse, G.; Hafner, J. Ab initio molecular-dynamics simulation of the liquid-metal amorphous-semiconductor transition in germanium. Phys. Rev. B: Condens. Matter Mater. Phys. 1994, 49, 1425114269.

(61) Kresse, G.; Furthmüller, J. Efficient iterative schemes for ab initio total-energy calculations using a plane-wave basis set. Phys. Rev. B: Condens. Matter Mater. Phys. 1996, 54, 11169-11186.

(62) Kresse, G.; Furthmüller, J. Efficiency of ab initio total energy calculations for metals and semiconductors using a plane wave basis set. Comput. Mater. Sci. 1996, 6, 15-50.

(63) Perdew, J. P.; Ruzsinszky, A.; Csonka, G. I.; Vydrov, O. a.; Scuseria, G. E.; Constantin, L. A.; Zhou, X.; Burke, K. Restoring the Density-Gradient Expansion for Exchange in Solids and Surfaces. Phys. Rev. Lett. 2008, 100, 136406.

(64) Krukau, A. V.; Vydrov, O. A.; Izmaylov, A. F.; Scuseria, G. E. Influence of the exchange screening parameter on the performance of screened hybrid functionals. J. Chem. Phys. 2006, 125, 224106.

(65) Perdew, J.; Burke, K.; Ernzerhof, M. Generalized Gradient Approximation Made Simple. Phys. Rev. Lett. 1996, 77, 3865-3868.

(66) Blochl, P. Projector augmented-wave method. Phys. Rev. B: Condens. Matter Mater. Phys. 1994, 50, 17953-17979.

(67) Gajdoš, M.; Hummer, K.; Kresse, G.; Furthmüller, J.; Bechstedt, F. Linear optical properties in the projector-augmented wave methodology. Phys. Rev. B: Condens. Matter Mater. Phys. 2006, 73, 045112 . 